\title{
'Place' as conceptual centre: a methodological focus on the bodily relations, movements and expressions of children up to three years of age in kindergarten
}

Karin Hognestad, Telemark University Collage, Norway.

Karin.Hognestad@hit.no

Marit Bøe, Telemark University Collage, Norway.

Marit.Boe@hit.no

\section{Abstract}

The purpose of this article is to show how attention on 'place' can be productive in methodology concerning the bodily relations, movements and expressions of children up to three years of age who are enrolled in kindergarten. While research that has adopted a hermeneutic and phenomenological approach has contributed to important knowledge concerning young children, we propose re-thinking methodology that takes children's bodily relations, movements and expressions into concern. Using 'place' as a lens, we show how power relations are interrupted and allow for alternative ways for the researcher to relate to data. Inspired by Somerville (2010), elements of place are situated at the centre of the research analysis. The three key elements of place that are put to work are as follows: our relationship to place is constituted in stories and other representations; place learning is local and embodied; and place is a contact zone for cultural contact. The paper is part of a research project which explores how place can be more explicit in educational practices to strengthen kindergarten as a learning arena. We seek to explore how place relations work and what they have the possibility of producing in the analyzing process.

Keywords: early childhood, bodily relations, movement, expressions, place.

\section{Introduction}

In Norway, researching young children has been strongly influenced by a hermeneutic and phenomenological approach (Bae, 2004; Greve, 2005; Løkken, 2000). In phenomenological thought, the singular self-autonomous subject is fundamental to understanding being. Here, agency has been thought of as a property that is owned by the individual subject, and the subject has been understood as the subject-of-will (Davies, 2010). Methodologically, the individualised subject of phenomenology has certain implications for research on young children, as the researcher will draw her attention towards the child's inner experiences, choices and meanings. The researcher is encouraged to focus on the relationship between herself and the child, and although she tries to grasp the child's views without placing him or her in a lesser position, the data comes from the individual subject and his or her sense of the world. Recognition of children's views is important in considering children's participation in research; however, we think that it creates some dilemmas. According to Pacini-Ketchabaw and Nxumalo (2010), recognition is embedded in an identity-focused paradigm which is based on recognition from 'the other'. If we are to follow a research practice that assumes a stabile identity, the child is put at the centre of the research as someone the researcher needs. From a dominant position, the researcher is encouraged to highlight the child's views, and what we might do in these relationships is reinforce the researcher-child dichotomy as if the child's 
views must be considered important from the start. Instead of a practice of recognition where the researcher and child are positioned as each other's counterpart, we think it is necessary to shift towards methodologies that tone down the power of the researcher and the child as the only subjects involved. Practicing the concept of recognition situates the subjects (the researcher and the child) as fixed identities at the centre of the research, taking for granted the environment where the research is taking place. In this approach, the identities of the child and the researcher are seen as stable, as if they are separated from their beings in a particular place. Methodologically, the environment would be considered of less importance in the research process. Young children's bodily relations, movements and expressions in the world require openness to what might happen, and they demand a broader understanding of being in the world. This gives ways to develop a re-thinking of subjectivity and an acknowledgement of the material environment and landscape as active agents in the process of being (Davies, 2010; Hultmann \& Lenz Taguchi, 2010; Sandvik, 2010; Somerville, 2007, 2010).

The post-structural concept of the subject as unfixed and unstable, always in the process of becoming, is linked to the conditions of the possibilities that a certain place offers, including allowing for non-human subjects (Davies, 2010). Re-thinking subjectivity in research on young children and its methodological implications has been introduced by several researchers (Hultmann \& Lenz Taguchi, 2010; Johannesen \& Sandvik, 2008; Rossholt, 2009; Sandvik, 2010). Recently, this research has been engaged with the child and his or her environment as contextual and discursively inscribed (Hultman \& Lenz Taguchi, 2010), thereby challenging the anthropocentric view that puts humans at the centre, where the researcher is viewing the data from a privileged and hierarchical point of view (Hultman \& Lenz Taguchi, 2010). Considering a re-thinking of the subject including the material environment and non-humans as mutually agentic, constructing discursive practices, puts the researcher in a different position.

In our research, our interest is on exploring new approaches to methodology which considers children's relations to place. This means that we specifically look for the force within a place with its material elements present. For us as early childhood researchers, this is an unfamiliar way of analysing data, because we are used to conducting analyses from a researcher-child position, where the human subject rises above elements of place. Instead, we are drawn towards focussing on other elements than the human subject, such as the landscape, nature, toys or things. Using place as a lens enables us to deconstruct the ways in which we view the world that we take for granted, and it allows us to see things differently. We argue that there is a need for a re-thinking of the researchers' position and the power relations in methodologies in the early childhood field, and we argue that 'place' can make an important contribution in relation to this.

While research that has adopted a phenomenological approach has contributed to important knowledge about the youngest children in kindergarten (Bae, 2004; Greve, 2005; Løkken, 2000), our intention with this paper is not to dismiss this approach, but rather, to question the power of the researcher, and shift towards a methodology that accounts for children's bodily relations, movements and expressions in a different way. The increasing emphasis on children's rights claims for re-thinking methodologies, but this could also lead to an even stronger focus on the individual autonomous subject, or the subject-of-will in research. In this paper, we shall argue that the youngest children's rights are expressed through their place relations, and therefore, must have an impact on how we are conducting research. With place as the centre of our research, we try to show how the decentring of the researcher and human beings as the only active agents involved can contribute to thinking about methodology differently.

When engaging in collaborative deconstruction (Lenz Taguchi, 2010) with pre-school teachers in kindergarten, we explored what happened to us as researchers, as well as the analyzing work, when place was put at the centre. Our starting point for exploring place methodology is a photograph of the outdoor environment taken by us in a local kindergarten. In the first part of the paper, we shall 
introduce place as a framework in relation to young children's bodily relations, movements and expressions. In the second part, we shall show what place can do in the analyzing process, before we take up some concluding discussions of the possibilities that place methodology can offer in relation to researching young children.

\section{'Place' as a framework}

Place based methodology can be regarded as a resistance to methodologies that separate place relations in the data collection and analyzing processes. Place as a framework opens up a new dimension in the analyzing process which can contribute to a different kind of knowledge. This kind of knowledge production is closely related to place and the material environment, and it does not seek evidence and certain truths. Place methodology should be viewed as a resistance to evidencebased research. Reconceptualised research methodologies have also been introduced by other researchers (Otterstad, 2006; Rhedding-Jones, 2007; Sandvik, 2010).

Place as a framework emerges from critical place theories that connect humans to local places through direct experiences, reflections and actions (Gruenewald, 2003, 2005; Smith \& Sobel, 2010). Adopting a feminist poststructuralist and postcolonial approach, Somerville $(2007,2010)$ has outlined three key elements as the conceptual framework in what she calls an emergent arts-based methodology: that our relationship to place is constructed in stories (and other representations), that the body is at the centre of our experience of place and that place is a contact zone of cultural contact. The methodology is emergent because of the possible changes in place that can contribute to new place stories. It is arts-based because stories can emerge from different forms of expression, such as bodily expressions and movements and sensory experiences. A methodology considering 'place' opens up a relational ontology where humans and non-humans have the possibility of becoming 'other' in the space between the self and the world (Somerville, 2007). The ontology of the subject is one of becoming with a focus on the participatory body in a dynamic process of being. Furthermore, the process of becoming gives way to possible transformations in relation to place. We argue that the process of becoming and body-in-process must be taken into consideration when researching young children (Eide, Hognestad, Svenning, \& Winger, 2010; Rossholt, 2009). Several researchers have taken such children's bodily relations, movements and expressions into account (Greve, 2005; Hultmann \& Lenz Taguchi, 2010; Løkken, 2000; Olsson, 2009; Rossholt, 2009; Sandvik, 2010), but body-place relations that consider humans and non-humans as discursive agents in the process of becoming have been underexposed in previous research (Somerville, 2007). An emergent place methodology has strong implications for how researchers enter the educational field and how they relate to children and the environment in research. 'Place' as the centre in research opens up a different research position where place-data itself will have an impact working upon the researcher as much as the researcher works upon the data.

An emergent arts-based methodology leads to a wider understanding of knowledge construction, by not separating being and thought, as in the Deleuzian plane of immanence. Inspired by Deleuzian philosophy, Sandvik (2010:31) explains what the implications of decentring the subject can have for methodology:

In other words we have to move towards a decentring of the researcher as a subject and start engaging in the flows, intensities and speed that emerge from different parts in the machineries in action (human and non-human). This opens up a whole range of processes that create possibilities for a variety of elements to have a say in the research analysis.... (Sandvik, 2010:31)

In her research, she allows different sources, such as art work and play, as data in the process of becoming. In order to generate a wider understanding of knowledge construction, she puts to work 
non-human forces and explores how they are equally at play. When we put to work an emergent arts-based methodology, we look upon it as an exploration of a relational materialist methodology that understands the child as emergent in place relations (Hultmann \& Lenz Taguchi, 2010). This ontoepistemological approach does not create any divisions between knowing and being, as all nonhumans and humans in a particular place have the capacity to generate new thoughts and bodily relations.

An onto-epistemological thinking thus clearly decentres the researcher as knowing subject and takes beyond the dominating subject/object, human/non-human, as well as discourse/matter and nature/culture dichotomies: it becomes impossible to isolate knowing from being and discourse from matter; they are mutually implicated. In terms of producing knowing as an educational researcher, this is about understanding the world from within and as part of it. (Hultman \& Lenz Taguchi, 2010:539)

Methodologically, arts-based methodology emphasizes that as humans, we are always part of place relations and we cannot detach ourselves from a particular place. Through place participation, new place relations and knowledge can be produced. Moreover, place as a productive force in methodology values place relations and the stories connected to a particular place. Somerville mentions this place knowledge as certain place literacy (2007).

I learn these place literacies through many layered stories, including creation stories, childhood experiences (...). They are all filtered through the contemporary personal life (his) stories and concerns of the individual partner researchers. We visit places together and the physicality of place also tells its own story.......The process of making visible the contradictory and contested stories of 'connection, exploitation and care' is a step towards new place literacies. (Somerville, 2007:7)

Place literacy emerges from practices of knowing in being and is connected to our being, belonging and becoming in a particular place. On this immanent plane, place literacy is not to be understood as the product of the individual subject, but something that lies outside the individual subject. In fact, it is a product of the complex net of relations provoked by the Deleuzian concept lines of flight that are activated in particular place relations. It makes us wonder what impact place literacy can have on methodology concerning young children and for us as new researchers. Rhedding-Jones (2007) suggests that new researchers should think about how their ontology can strengthen their research, and this is what we are trying to do in exploring how place methodology can be productive. Connected to this way of being and knowing, place as a contact zone (Somerville, 2007, 2010) can have a huge potential in methodology, since different place stories can emerge from deconstruction that involves what Somerville refers to as a discomfort zone $(2007,2010)$. To activate the contact zone, we have employed diffractive readings as a methodological strategy. According to Deleuze, diffractions emerge from the concept event and are to be seen as effects of interferences. In analysing the data, this meant that we were looking for events of activities and encounters evoking transformations and change in the performative agents involved (Hultman \& Lenz Taguchi, 2010:535). Both humans and non-humans are capable of diffractive movements and interferences. Referring to the metaphors of Barad, Hultman and Lenz Taguchi (2010:535) explain diffractions as transformations of waves in the sea. Changes in waves occur when the wave meets an obstacle, like a stone in the sea, and then the wave continues, but in a new and different form. Exploring these interferences made us aware of processes of becoming in a certain place and what they might do to us as researchers as well as the children and the material environment. The Deleuzian concept of diffraction can highlight the potential of a contact zone and the implications that new thoughts and place relations can have for researching young children. Inspired by Hultman and Lenz Taguchi (2010), we shall further show in this paper how a diffractive methodology has the potential to change place relations and the power within, and we shall argue that place literacy can emerge from these interferences in an in-between place and the subjects. 


\section{Place as a lens - a productive force in analyzing data}

Engaging in collaborative deconstruction (Lenz Taguchi, 2010) with three kindergarten teachers, the aim in this part of the paper is to show what happened when an emergent arts-based methodological approach was made productive. Our aim was to specifically open up and deconstruct place stories using the three elements of place mentioned earlier (Somerville, 2007, 2010). Using deconstruction as a strategy demanded us to install ourselves into a certain place, since the process of deconstruction always starts from the discourses in which our place relations are embedded (Lenz Taguchi, 2010). It is a strategy that can be done with and from within place, where we added the concept of diffraction as a potential avenue that would lead to new place stories. In a diffractive 'seeing' and 'reading' of the data, we used our embodied place relations as we installed ourselves in the process of data analysis. We were not interested in uncovering what happened when the photo was taken; rather, we were looking at the photograph as an event wherein we were relating to the data.

It is an event of becoming-with the material artefact of the photograph, while engaging in diffractive 'seeing' and 'reading' with it. A diffractive 'reading' is thus not a reading of a photograph as in taken-for-granted understanding, but a reading with the photograph in your encounter with it. In this event something new is created with the data. (Hultman \& Lenz Taguchi, 2010:537)

The photograph that we chose for this paper displays children engaged in outdoor play in an everyday setting in their pre-school. From May to October, children spend about 70 per cent of their time during the day outdoors in Norwegian kindergarten (Moser \& Martinsen, 2010). This means that outdoor places are of huge importance to educational settings in Norwegian kindergartens. We chose this photograph because it is recognisable in the early childhood field, both internationally and nationally; children on a slide can be considered as representing a typical outdoor activity. With place as a lens, the photograph opened up a discussion as to what different beings and 'becomings' emerged from place relations. We were curious about what happened when place was facilitated in the discussions regarding outdoor play and learning. The photograph made possible professional stories and discourses to appear, and with place as a lens, this made us work with deconstruction in a new way, with the potential to develop new stories about outdoor educational settings. We began the discussion by introducing the photograph: 


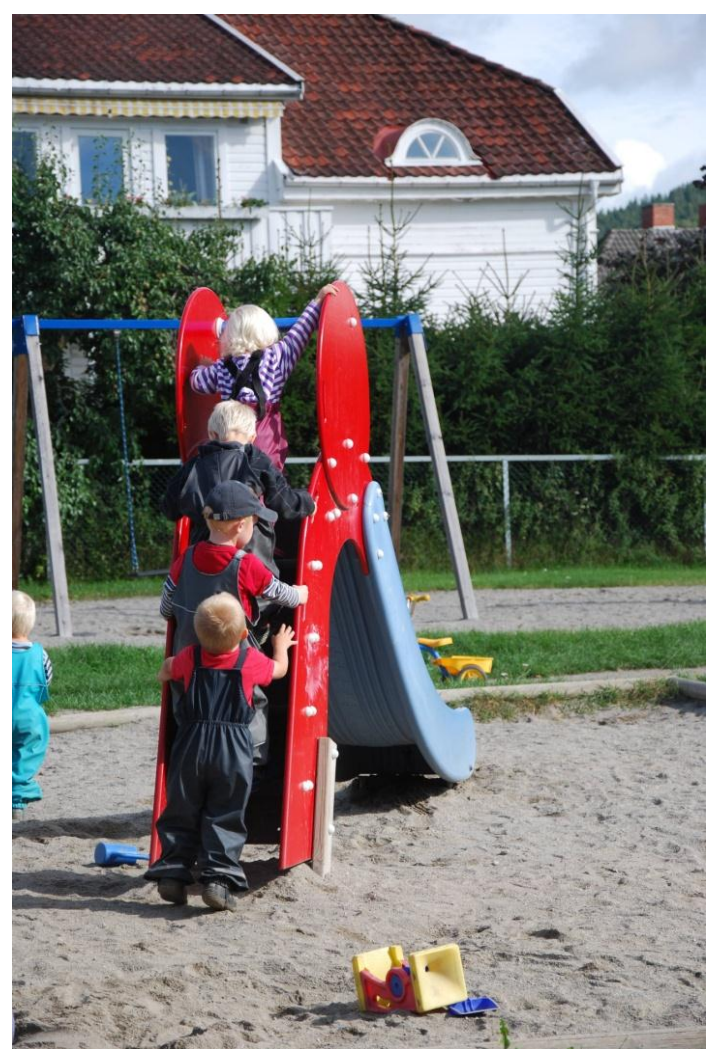

\section{Bodily relations, movements and expressions}

When we read the photograph together with the kindergarten teachers, one of the first things that came to our minds was the significance of outdoor play in relation to 'freeplay'. One of the first places that young children make use of and come to know is the outdoor environment in kindergarten. In 'freeplay', which is a daytime activity in which children participate, the children are allowed to choose a 'place' and ways to inhabit it. However, power is present in the form of the control exercised by the pre-school teacher's choice of materials and places themselves.

The play is generalised by the slide. When I look at the slide, it is obvious to me how the children will use it. I have often regulated how the slide is supposed to be used.

I look at this as something that is highly regulated. Here, you have do this. How do I use my power in relation to the children?

Thus, in reading the photograph with place as a lens, we discovered that we had two different readings. First, we discussed the critical issue of 'freeplay' as both a physical and metaphysical place. Even though place was our starting point, it was difficult to read beyond ourselves as the centre of knowing, as professionals who regulate the children's movements in 'freeplay' by the discursive agency of the slide. It was also tempting to discuss what 'freeplay' was, and initially, this seemed to rise above the different becomings that were possible between the children and the slide. On the other hand, it was also easy to give the slide agency in a way that designated the children as passive recipients. Focusing on deconstructive readings, we found ourselves captured by the verbal articulation and the contradictions in language, which almost made us forget that agency is understood as a force that emerges in the intertwinement between the different subjects involved (Hultmann \& Lenz Taguchi, 2010). Instead of paying attention to the encounter between the children and the slide, we tried to make the contact zone productive in a way that established new agencies when different subjects came to play. 
The discussions took another direction when we looked deeper into what might possibly become of the children and the adults in this in-between space. The materiality of the slide, with the stairs connecting to the children's bodies, encourages and disciplines the children's bodies in a certain way. The children relate to the stairs as they climb up and then slide down the slide, and in this contact zone, diffraction transforms the children's bodies into certain movements as the slide and the children play together. Discursively, embedded in this event, there are certain place relations and becomings that are made possible. The stairs invite the children's feet to climb them, assuming that the bodies can position themselves in a row. The row of bodies standing in a vertical line can be read hierarchically, and understood as if the child at the top has the power to decide what will come next. However, the child standing in last is positioned in a state of waiting, given less power to control the body. The child at the top is able to hold onto his position as long as he wants, until the others push him or tell him to move. Hence, the bodies become different in relation to how they are adjusting to the slide and its discursively agentic way of being. Coming into play with the slide, the bodies have different agencies through their speed, the wind in the hair, the tickling in the stomach and the standing in line and climbing of the stairs. The different styles of becoming that are made possible in these moments of intertwinement open up the study of different power relations as the children's bodies are transformed by diffractive movements.

The next dialogue shows how the story emerged when we allowed embodied place stories to work in the analyzing process. Further, these stories showed how politics can influence the emergence of different styles of becoming.

If we think of the element of place pedagogy, that place learning is embodied.

What could my body learn by moving there, in a queue with a lot of people? But as a matter of fact, not long ago, I joined a meeting with teachers at school who were discussing the transfer from kindergarten to school, and they told me that practising standing in a queue in kindergarten would make the transfer easier for the children.

Deconstructing the photograph made us discover how a queue and standing in line are viewed as bodily movements which are looked upon as important social skills in accordance with school preparation. The dialogue raised discussions about political ideas and the governmental control of preparing children for school. Place as a lens activated a political discussion that seems to have the power to highlight the children's actions and social competences, where place was looked upon as a means to achieve a goal, rather than the significance of the place relation itself. Therefore, the material environment here was looked upon as secondary to the children's actions, when the children and the teachers were emphasized as agentic subjects. However, an interesting discovery in this discussion was when we related the relational materiality approach to the national curriculum. When opening up this wider understanding of being, in a plane of immanence, we were able to think differently about how pre-school teachers could be active in children's processes of learning (MER, 2011). This way of reading body/place relations has the potential to open us up to new ways of understanding the disciplinary body.

\section{Place that provides opportunity for exploration}

I came across a fallen tree

I felt the branches of it looking at me

Is this the place we used to love?

Is this the place that I've been dreaming of?

(Keane, 2004) 
The emergent arts-based methodology encouraged us as researchers to use different place stories in the analyzing process. In her research, Sandvik (2010) utilises different pieces of art in the analyzing process to generate new thoughts. This approach argues that everyday life and our being in the world cannot be left out in methodology. Inspired by a relational ontology that untangles the distinction between humans and non-humans, we employed a song and let this work in the collaborative deconstruction. As everyday life affects us in different ways, place stories can emerge from different sources, such as a song. Quoting Deleuze, Hultman and Lenz Taguchi (2010:536) wrote the following: 'Something in the world forces us to think'. This was exactly what happened when a song by Keane surprised the researcher one day when she was walking her dog while listening to her iPhone. This sudden discovery of the song emerged in a moment of diffraction which brought up feelings attached to place, and sharing this song as data in the analyzing process, the group was able to look at the photograph from a different perspective.

Somewhere only we know - it can be in this room as well as in a fantasy.

The elements that we brought into place pedagogy are the elements of creativity and creative thinking.

Is place pedagogy the same as what Nordin Hultman talks about?

Well, I believe it could be. She talks about the importance of time and space, and this can also include the outdoor space.

Yes, a meeting with people and space.

But it is something more than that. It is not only a physical place, but also a metaphysical place, like what does this place enable?

But, here, creativity is important.

But what was funny was when we brought the song into the analysis, and it became so clear that there are a lot of metaphors connected to place, what place can do... it will always affect us. Place will always affect children, because they use it all the time.

But is it so that creativity is not possible when place is strongly regulated? Is creativity important in the possibility of becoming someone else?

If we think of the slide and the possibilities present, does the slide have the potential to change?

The dialogue gave way to possible new ways of studying place relations. Place methodology separates all binaries, and relations are not put in boxes that divide one from another. Place becomes a bridge to make one's own embodied stories productive in methodology. When we first examined the photograph, it was difficult to read place on an immanent plane because we were so used to putting our professional practice and our human subject at the centre of knowing. Since we were all former pre-school teachers, it was easy to reflect on our own practice and what might have happened when the photograph was taken. We positioned ourselves outside the data instead of remaining within the data (the photograph), and we found ourselves maintaining the dominant borders of our being in the world. From an outside perspective, we were drawn to study the photograph as a past experience connected to our own professional practice. From this position, outdoor place was very recognisable, intimate and personal, and the feelings that we shared with each other made it difficult to move outside the familiar and dominant discourses about outdoor place. One of the more emotional stories was when we experienced ourselves making judgements about outdoor life in kindergarten. Even though we thought we were acting in a fair and ethical 
manner while analysing the photograph, we found ourselves relying on stereotypes, judging outdoor places as good or bad. This made us feel powerful, as if we were able to establish a subject position that separated our being, enabling us to be someone else. By identifying so strongly with the preschool teachers and at the same time positioning ourselves as the other, judging the outdoor place seemed like a critique of the teachers' pedagogical practice and professional values.

Introducing the song as data had the effect of slightly shifting our attention to tone down ourselves as the only subjects that had something important to say. It supported the analysis in another way that allowed us to use our professional stories differently. The lines in the song, 'I felt the earth beneath my feet', 'I knew the pathway like the back of my hand' and 'is this the place that I've been dreaming of' connect the strong relationships and belongings to place, and made it almost impossible to not become with the data. These metaphors strengthened the intertwinement between place relations, and our attention was drawn to what was happening when this song and the photograph together with us came to play with each other. Reading these data horizontally, as researchers, we almost lost our position to judge the data, and instead, a new position, or style of becoming, emerged. The becoming of the decentred researcher relating with the data forced us to read the data differently from the way that we normally would. As Hultman and Lenz Taguchi (2010) point out, diffractive reading is something other than the phenomenological concept of reflecting, where the researcher creates a distance from the data whereby the intention is to reveal specific instances or cases of being in the world. Instead, the researcher activates all his or her place relations in reading the data, which highlights the transformations taking place in the contact zone.

The diffractions that emerged from the data in the contact zone made us think about the places provided for children in education. Outdoor places are an integral part of the curriculum (MER, 2011), and with the focus on children's rights, the question is in what ways the youngest children can participate in curriculum activities. A dominant practice, especially in relation to young children, is to plan activities for them to do, rather than providing them with opportunities to create and explore their own environment. Discussing places where children can influence and be encouraged to participate in activities that can effect change, it became clear to us that place as a contact zone is important in relation to children's participation. In discourses related to children's participation, we are used to focussing on children as active agents, the power relations between children and adults and children and the kindergarten community (Kjørholt, 2011). The song 'Somewhere Only We Know' provided new ways of understanding children's participation because it turns the focus towards place and children's being, belonging and becoming in a place. Centralising place gave us the opportunity to re-think participation, because participation must be considered in relation to place, which means thinking of participation as more than a two-way relationship. Place seems to be hugely significant to children's participation, and strong place regulations can prevent participation and children's creative thinking and desire to move, relate and express themselves outside the order of things (Bøe \& Hognestad, 2010). Place as a contact zone enables us to re-think participation as an individual right of the human subject. Through bodily relations, movements and expressions, children make places; but place makes them as well, and therefore, participation must consider and include the material environment as an active performative agent creating power relations.

Outdoor place is constituted as a place for activity and play, where children have the possibility to create new ways of inhabiting that place. However, this depends upon whether place can be regarded as a contact zone. In the national curriculum, creative thinking is an educational goal (MER, 2011), but if children's teaching and learning are strongly standardised and regulated, place can reduce the children's transformations and becomings (Bøe \& Hognestad, 2010). Our research shows that the material environment and the child are in a state of becoming with each other with the possibility of transformation. What they are transformed into depends on how place as a contact zone is activated and the power relations which emerge. In the encounter between the child and place, certain transformations are able to emerge, depending on the different qualities of the 
material environment and landscape. Children's being, belonging and becoming are affected by the qualities of a certain place and the discourses inherent in them, and it is, therefore, important to study the diffractions and interferences to explore what they can provide in relation to children's place literacy.

These shifting interferences and movements in place, in a contact zone, challenge the children's agencies with regard to the ways that they are able to create new place stories. Thus, moments of diffractions can be regarded as what Somerville (2007:14) calls borderwork moving between and across boundaries: 'we found the discomfort zone as a productive place of productive tension based on difference and characterized by mobile and shifting boundaries constructed within this emotional and intellectual border work'. In the multiplicity of encounters that a place can provide, different possible diffractions are able to emerge between young children's place literacy and the local environment. In relation to place as a contact zone, interferences caused by diffractions can be understood in relation to children's active participation. Children's places can provide different knowledge than the places that adults have designed for children (Rasmussen, 2004). Children are active participants in place-making through peer relations and their interactions with the material environment, and in the encounter between children's places and places for children, dominant discourses on what outdoor life in kindergarten should be are challenged. Interferences in place relations encourage place literacy when the child becomes with the place and the place becomes with the child.

Place as a contact zone, with its potential for transformation, can inform methodology in a productive way by adopting a framework of desire (Tuck, 2010). In our diffractive readings, the concept of desire was used productively, as we were concerned about the transformations which emerged in the events and encounters between the agentic subjects. The concept of desire, Tuck (2010) emphasizes, is aided by Deluze's concept of desire which emerges in any network of relations as a desire that is becoming. In a plane of immanence, desire is understood as an event (haecceity), or a moment in which the subject knows itself to be immanent (Davies, 2010). Instead of understanding desire as sudden, unconsciously meaningless events, as emerging in processes of which we are mostly unaware, Tuck argues that desire 'is purposeful, intentional and agentic; that it can teach itself, craft itself, inform itself; that it can make decisions, that it can strategize' (Tuck, 2010:645). Here, desire is not looked upon as an absence, and in relation to young children, Olsson (2009) has shown how the concepts of desire can be productive in young children's knowledge construction. Conceptualising desire as an active agency, as a desire capable of creating events, linked to the past and the future, desire has the potential to inhabit place in new ways. When we took up diffractive reading as a strategy (Hultman \& Lenz Taguchi, 2010), desire was not merely something that just happened. In the different encounters with certain interferences involved, desire was taken up as a productive force to move thoughts further. As Davies states, agency

lies in the capacity to stand back from thought, to see what it assumes and what it might accomplish, and to imagine how it might differ. It lies in the capacity to critically examine thought, and to generate new thought, using not just intellect but also imagination and the senses (Davies, 2010:67).

For us, this does not meant placing our human subject back at the centre of the analysis, or positioning ourselves outside of the data, but rather, allowing our place literacy to be activated through our being, belonging and becoming. In relation to the contact zone, the framework of desire constitutes place literacy as certain body/place knowledge which cannot be separated. 


\section{'Place' as the centre in methodology - concluding discussions}

In this paper, we focussed on methodology in relation to the youngest children in kindergarten. Taking up an emergent arts-based methodology (Somerville, 2007, 2010) we explored what happened when place was put at the centre of the analyzing process. Analysis shows how we have been struggling with methodological approaches that highlight the human subject as the centre of knowledge construction. Moving towards emerging possibilities of being, where being includes all humans and non-humans present in a particular place, we were open to the possibilities of an emergent-arts-based methodology and its contribution to research on young children.

Place as a lens re-positioned us as researchers in a sense of relating that we had not experienced before. Relating in a material environment and landscape has practically been taken for granted and intentionally overlooked to avoid disturbing data analyses. However, Sandvik (2010: 37) argued that a methodology which embraces a plane of immanence has the potential to allow thoughts to produce themselves almost artistically as they come along. These thoughts are able to emerge from body/place relations, as our thoughts are not separated from place.

The individuality of the days, the seasons and years pass through the researcher whenever $s /$ he reads and writes. So do the sunrises and sunsets that continuously light up and darken my desk. Additionally I as researcher pass into the chair on which I sit, the sound of the computer keyboard when my fingers touch the keys, and the little lamp on the desk plugging into memories of smells in barnehager (Children's centre) and then colours of a painting.

(Sandvik, 2010:33)

As new researchers, we experienced how a relational ontology focussing on relations in something rather than relations to something can be useful in methodology and for the educational field. Since everyday life is to be regarded as processes of becoming, we think that it is important that methodologies take place into concern, since young children's bodily movements, relations and expressions are not detached from place. Taking up the framework of desire (Tuck, 2010), we experienced how diffractive readings can be productive and have significance for the educational field and children's place relations.

The national curriculum emphasizes children's bodily learning, as it states the following: 'How the educators meet children's expressions through body, language, feelings and social relations have an impact for their learning' (MER, 2011: 33, our translation). The quotation shows how the practitioner researcher is encouraged to remain in the discourse of the human subject as the only agentic subject present. Embedded in an identity-focussed paradigm, research tends to focus on a two-way relationship which makes it difficult to step back from the habitual way of reading data and move to a new and unfamiliar position. As researchers and professionals, we are used to controlling the research process from an outside position. Bringing different materials such as a song or a photograph into the analyzing process and acknowledging the agentic force of these materials has the ability to transform our thoughts in unpredictable ways.

A relational materialist methodological approach has strong implications not only for the ways we think about the children and the educational practices we research, but also for the way we think about our research and ourselves as researchers. (Hultman \& Lenz Taguchi, 2010:534)

By remaining in the data instead of analysing the data from an outside position, we are forced to 'understand identity as an effect of events that so to speak take place on the "surface"' (Hultman \& Lenz Taguchi, 2010:531). This can be of huge importance in relation to how professionals and researchers speak and articulate children's movements, relations and becomings. Instead of talking about the children as something they are, or as different from each other, from adults and from things, we are encouraged to create a language to describe how human and non-human bodies differ 
in what Deleuze calls different styles of becoming (Hultman \& Lenz Taguchi, 2010). This is not meant to claim that human and non-humans are the same, but rather, to convey a difference where we seek to articulate how the subjects become different in themselves (Hultman \& Lenz Taguchi, 2010). Analysing data from a diffractive point of view makes us reconsider reflective methodologies that encourage us to step outside the data and, instead, talk about what happened in the past.

Sometimes, reflecting methodologies have the power to bring the attention towards the individual child and what the child is and does. Such a focus may contribute to toning down processes of becoming and the different place relations between the child and the environment. Therefore, a place methodology seems to be more productive in relation to young children, because place relations are an important part of these children's interactions and active participation.

Using the contact zone as an analytical framework has the power to make us read data differently, as we are able to identify absences in dominant stories and to create new stories. Focusing on the encounters between different agentic subjects in a contact zone allows for diffractions and interferences to be discovered and studied. These particular encounters are of significance to children's bodily participation because diffractions and their effects make premises for children's place literacy. Place literacy emerges from practices of knowing in being, and it is connected to our being, belonging and becoming in a particular place. Methodologically, it is, therefore, important to study place as a contact zone and the place stories which emerge to see what they can provide for children's place literacy.

And if you have a minute why don't we go

Talk about it somewhere only we know?

This could be the end of everything

So why don't we go.

\section{References}

Bae, B. (2004). Dialoger mellom førskolelærer og barn: en beskrivende og fortolkende studie. Oslo: Høgskolen i Oslo.

Bøe, M., \& Hognestad, K. (2010). Critical thinking in kindergarten. Childhood and philosophy, 6(11), 151-165.

Davies, B. (2010). The struggle between the individualised subject of phenomenology and the multiplicities of the poststructuralist subject: the problem of agency. Reconceptualizing Educational Research Methodology, 1(1), 54-68.

Eide, B. J., Hognestad, K., Svenning, B., \& Winger, N. (2010). Small children's voices in research. Reflections on research ethics in relation to small children's everyday life in kindergarten. (Små barns stemmer i forskning. Noen refleksjoner om etikk i forskning om små barns hverdagsliv i barnehagen). Barn (3), 31-46.

Greve, A. (2005). Friendship relations among toddlers. Australian Research in Early Childhood Education, 12(1), 81-92.

Gruenewald, D. A. (2003). Foundations of Place: A Multidisciplinary Framework for Place-Conscious Education. American Educational Research Journal, 40(3), 619-654. 
Gruenewald, D. A. (2005). Accountability and Collaboration: Institutional Barriers and Strategic Pathways for Place-based Education. Ethics, Place \& Environment, 8(3), 261-283.

Hultmann, K., \& Lenz Taguchi, H. (2010). Challenging anthropocentric analysis of visual data: a relational materialist methodological approach to educational research. International Journal of Qualitative Studies in Education, 23(5), 525-542.

Johannesen, N., \& Sandvik, N. (2008). Små barn og medvirkning: noen perspektiver. [Oslo]: Cappelen akademisk forlag.

Keane (Artist). (2004). Somewhere Only We Know from the album 'Hopes and Fears' [Song].

Kjørholt, A. T. (2011). Kindergarten as playground for autonomy and choice. Oslo: Universitesforlaget.

Lenz Taguchi, H. (2010). Doing collaborative deconstruction as an 'exorbitant' strategy in qualitative research. Reconceptualizing Educational Research Methodology, 1(1), 41-53.

Løkken, G. (2000). Toddler peer culture. The social style of one and two year old body-subjects in everyday interaction. Trondheim: Norges teknisk-naturvitenskapelige universitet, Pedagogisk institutt.

MER (2011). Framework plan for kindergartens.

Moser, T., \& Martinsen, M. (2010). The outdoor environment in Norwegian kindergartens as pedagogical space for toddlers' play, learning and development. European Early Childhood Education Research Journal 18(4), 15.

Olsson, L. M. (2009). Movement and experimentation in young children's learning. Deleuze and Guattari in early childhood education. New York: Routledge.

Otterstad, A. M. (2006). Deconstruction - a 'door opener' to alternative practices in kindergarten. (Dekonstruksjon - en døråpner til alternative barnhagepraksiser). Barnehagefolk, (3), 40-48.

Rasmussen, K. (2004). Places for Children - Children's Places. Childhood and philosophy, 11(2), 155173.

Rhedding-Jones, J. (2007). Who chooses what research methodology? In Hatch, A. (ed). Early childhood qualitative research (207-221). New York: Routledge.

Rossholt, N. (2009). The Complexity of Bodily Events through an Ethnographer's Gaze: focusing on the youngest children in preschool. Contemporary Issues in Early Childhood, 10(1), 55-65.

Sandvik, N. (2010). The art of/in educational research: assemblages at work. Reconceptualizing Educational Research Methodology, 1(1), 29-40.

Smith, G. A., \& Sobel, D. (2010). Place-and Community-Based Education in Schools Abingdon, Oxon: Routledge.

Somerville (2007). Place literacies. Australian Journal of Language and Literacy, 30(2), 149-164.

Somerville (2010). A Place Pedagogy for 'Global Contemporaneity. Educational Philosophy and Theory, 42(3), 326-344. 